\title{
A GLIMPSE OF BLUE SHEEP (Pseudois nayaur) HUNTING IN API NAMPA CONSERVATION AREA (ANCA) NEPAL
}

\author{
Tek Bahadur Yakha', Mukesh Kumar Chalise',** \\ ${ }^{\prime} M a n a s l u$ World College, Chababil, Kathmandu, Nepal \\ ${ }^{2}$ Central Department of Zoology, Tribhuvan University, Kirtipur, Kathmandu, Nepal \\ *Corresponding author: mukesh57@botmail.com \\ (Received: March 30, 2021; Revised: September 18, 2021; Accepted: September 30, 2021)
}

\begin{abstract}
Higher altitudes of Api Nampa Conservation Area have become a hunting destination for the local people bringing a threat to blue sheep and other wildlife. Blue sheep has been a national concern in Nepal due to being the main prey species of snow leopard and trophy hunting. The purpose of this paper is to examine the impact of hunters in Api Nampa Conservation Area (ANCA), Darchula, Nepal. This study was carried out around Api Nampa Conservation Area in 2016. Mixed methods of questionnaires were developed to collect data, and quantitative analysis was done by applying SPSS 16. A hundred percent of hunters like to hunt in this protected area. The hunted animals were goral, blue sheep, barking deer, boar and tahr. Site-specific characteristics like vegetation density, terrain and rugged land topography often vary markedly across surveys. Due to the regular and yearly use of grazing by the livestock in the area, it becomes imperative to study their feeding habits and document their food plants. Consequently, poaching and livestock grazing are important challenges for the conservation of blue sheep. Hunting, deforestation, forest fires, grazing and shifting agriculture are identified as major threats to the wildlife of Api Nampa Conservation Area. Envisioning, critical thinking, building partnership in decision-making, awareness, and stringent action against hunting activities must be adopted early. Api Nampa Conservation Area has received little research attention from grassland ecologists and specialists in pastoral management.
\end{abstract}

Keywords: Api-Nampa, blue sheep, conservation, hunting, wildlife.

\section{INTRODUCTION}

Naur, bharal, blue sheep (Psendois nayaur) are found throughout, especially Southeast Asian Nations (China, Bhutan, northern India, northern Myanmar, Nepal and northern Pakistan) which are categorized and listed as least concern in view of their low risk, wide and large population. Also, it is categorized as Least Concern and has second-class protection in China (IUCN, 2003, 2006). The primary purpose of the hunting program is not the generation of maximum funds; instead, the conservation of wildlife habitats (Frisina \& Tareen, 2009). The most important ungulate that snow leopard (Panthera uncia) shares throughout its habitat are blue sheep (Schaller et al., 1988, Chalise, 2016, DNPWC, 2019). In the 21st century, hunting in general and trophy hunting, in particular, are almost purely recreational. Recreational trophy hunting is the motor that drives a multi-million dollar global hunting industry. It is needed to establish strategies for the different hunting regions globally, which show that recreational trophy hunting is part of a triple-bottom-line approach to sustainable conservation. This approach includes social, economic and ecological considerations (Damm, 2008).

Unless the existence of biological limits is not sufficiently recognized, hunting is always deleterious for native species' growth. Hunting is no bravery nowadays, as in the medieval period. Blue sheep, Himalayan tahr (Hemitragus jemlabicus), goral (Naemoradus goral), Himalayan musk deer (Moscbus sp) are the large mammals found in this area. However, gorals and langurs are found at lower altitudes. There is a high possibility of the decline of these animals due to increased poaching due to unscientific and unregulated local hunting. The main objective of this study was to observe the hunting pattern and background of the local people.

\section{MATERIALS AND METHODS}

This study was carried out in Api Nampa Conservation Area in 2016. Primary data was collected from the direct observation of the animal and selected local people; secondary data was collected from various organizations. Knowledgeable persons of the village, the permanent residents, and sheep/goats herders of the place, had been already contacted, consulted and managed before departure to the field area. In this research, questionnaires developed by Oli et al. (2013) were used and developed according to the requirement. Observation of animals was done from 0700 hours to 1630 hours. Surveys were conducted from high vantage points along ridgelines in the morning when animals were likely to be feeding and before late afternoon. The ground vegetation was also recorded to examine the food plants and diversity on the forest floor. It was possible to obtain a picture of the existing plant communities, the degree of disturbance and the composition of the forests. 


\section{Study area}

The area is located in the northern part of the Darchula district of the far North-Western part of Nepal, covering 1,903 square kilometers (Fig. 1). It is situated between $29^{\circ} 30^{\prime}$ to $30^{\circ} 15^{\prime}$ north latitude and $80^{\circ} 22^{\prime}$ to $81^{\circ} 09^{\prime}$ east longitude. The topography extended around an altitude of $539 \mathrm{~m}$ to Api Himal, $7132 \mathrm{~m}$ asl. It is located along the southern slope of Himalayan ranges bordering with international boundary in the north with China, Nasku and Nau rivers in the southern boundary (Chalise, 2012; Yakha, 2014). Western boundary joins with Kumaun, Uttarakhand (India) and Baitadi and Bajhang districts of Nepal in the eastern border. This conservation area got its name after two famous Himalayan peaks, viz. Api and Nampa.

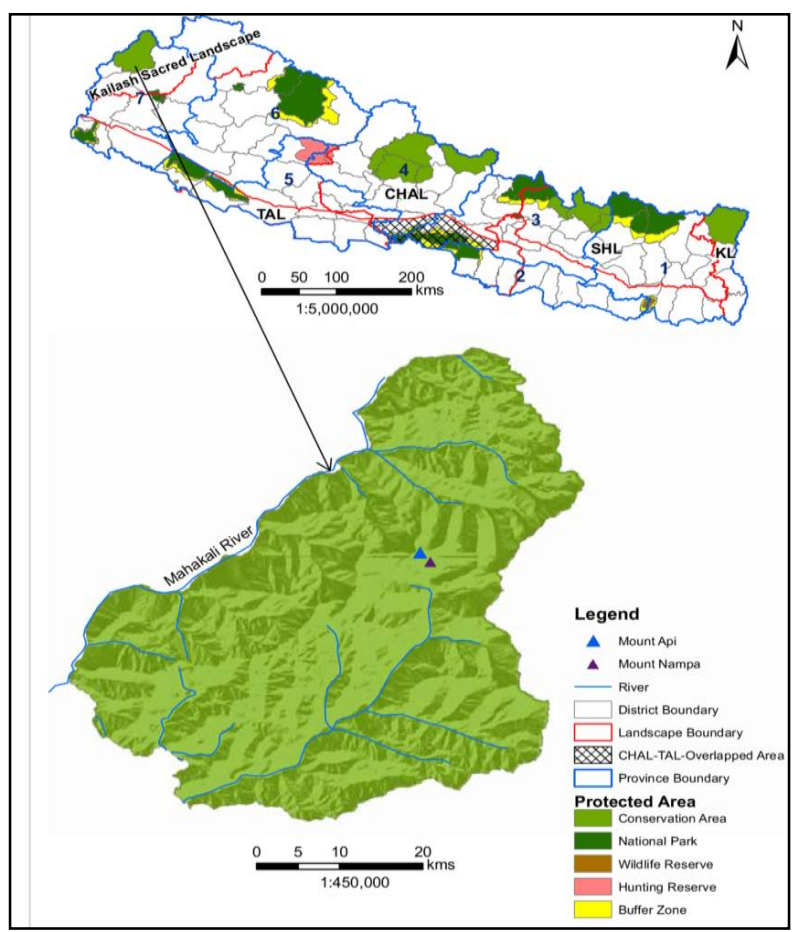

Figure 1. Location of Api-Nampa Conservation Area, Nepal (Google free maps downloaded).

\section{Data collection}

A population census was done to assess the natural occurrence and abundance of the present population of the blue sheep. Census was done at regular intervals and in each of the blocks separately. Some observation stations from where the maximum area of this bovid habitat was scanned and taken into consideration for field observation. Each block was covered by walking along the line-transect, and animals were counted as seen each time. At covering all blocks, we added all counts and taken as a census of our area. First, we traveled as reconnaissance survey along the target area of the upper part of Api plateau and recognized specific differences by observing the topography and existing habitat, and finally, specific blocks were decided. The binocular and photographic camera was used to scan numbers and classify them into different categories like age class, sex composition (Jackson \& Hunter, 1996). To facilitate the population census of the blue sheep, the entire habitat was divided into different census blocks based on natural barriers such as glaciers, deep gorges and steep valleys. Four stations were laid covering approximately $1.2 \mathrm{~km}$ from where the maximum area of blue sheep could be scanned.

For each observation, the herd size, sex and age composition and the following habitat parameters such as; habitat type, landform type, altitude slope and aspects were recorded. Care was taken to avoid duplication of counts in the blue sheep herds. The time interval of visitation was made punctual. Moreover, the herd sizes and sex also were accounted for duplicate counts.

\section{Data analysis}

Quantitative analysis was done by coding and transforming variables. SPSS 16 software was used for quantitative analysis. For Qualitative analysis, interviews and thematic analysis were transcribed based on grounded theory.

\section{RESULTS}

Altogether, 137 blue sheep were recorded by direct observation and supported by local people's opinions (Table 1).

Table 1. Association between place and the census of Blue sheep

\begin{tabular}{llcc}
\hline Total & N & Mean Rank & Rank number \\
\hline Young male & 23 & 50.48 & 1 \\
Adult female & 16 & 60.34 & 2 \\
Sub adult male & 10 & 61.2 & 3 \\
Adult male & 20 & 68.05 & 4 \\
Yearling & 42 & 73.6 & 5 \\
Unidentified & 26 & 87.02 & 6 \\
\hline Total & $\mathbf{1 3 7}$ & & \\
\hline
\end{tabular}

The respondents who had primary level education were $10 \%$ only as per the data collected from the survey station. Overall primary level group of respondents covered $90 \%$. It seems that the culture of education was poor before some decades. As some educated groups of youths are out of their village for their higher studies and/or searching for a job, they could not be contacted. The data in the table 1 indicates that conservation awareness of wildlife and natural resources is critical. All $(100 \%)$ of the participants' profession was a farmer. There was no report of female involvement in hunting.

All hunters like to hunt in this protected area. They used to hunt due to poor economic conditions as well as to join hands to mouth. They hunt for different purposes like meat, entertainment, medicine, skin and domestic 
expense. The prey hunt in the trip varied from $10 \%$ to $60 \%$ (Table 2). Gorals were the commonly hunted animal. Usually, one goral was hunted in each episode of the hunting trek. The hunted animals were found to be barking deer, boar and also tahr.

Table 2. Prey hunt in the trip

\begin{tabular}{lcc}
\hline No of prey & Frequency & Percent \\
\hline 1 prey & 12 & 60.0 \\
2 preys & 6 & 30.0 \\
3 preys & 2 & 10.0 \\
\hline Total & $\mathbf{2 0}$ & $\mathbf{1 0 0 . 0}$ \\
\hline
\end{tabular}

Out of the several tools used for hunting episodes, the common shut-gun was found to be a common tool for hunting the animals, and $65 \%$ of hunters used it. The remaining 35\% use trap for hunting. All (100\%) hunters have hunted tahr in their life. As per the $80 \%$ of respondents, they usually hunt one animal per trip. Sometimes they hunt up to 3 animals also. Hunters shoot any wild animals of either sex, whichever come across. They also expressed reluctance and had no further interest in tahr hunting but wanted to keep guns for self-security. They further stressed that the issue of license should be strict, better no issue of license.

Local stakeholders collect royalty from the visitors to the conservation area. The people expect more investment for community development $(75 \%)$ than conservation $(25 \%)$ from the royalty they collect.

\section{DISCUSSION}

Mammals are imperiled worldwide. Threats to terrestrial species are primarily from habitat loss or modification, and in some instances, from commercial, illegal, or unregulated hunting. Some species are negatively affected throughout the tropics by deforestation (Bowyer et al., 2019). Multiple values and functions of hunting will be ineffective if the legitimacy of conservation among rural people is felt weak. The diversity of the people and wildlife should be embraced and taken into account by the policymakers and the rural public. The success of biodiversity conservation has more to do with effectively managing for unique social characteristics and needs of the society than modern wildlife science (Frisina \& Tareen, 2009). Hunting is illegal in the conservation area, but it seems to be massive and beyond control. Though there is increasing awareness and information about the values and functions of hunting, sustainability of wildlife resources, rampant hunting is also found to be practiced in this conservation area. The local people have very little knowledge of the ecology, behavior and demography of the target wildlife species. The target species are musk deer, tahr, blue sheep and goral. With the diverging and little interest of locals on wildlife and less practical concern of the authority such as the local, provincial and central level, the conservation becomes challenging part.
However, interested local communities do their best from their understanding and resources.

October/November and June/July is the common response of the people for hunting blue sheep. For this period, the hunting of blue sheep is lured by 3 inches thick fur for jacket and carpet will be gained, more meat and fat. In summer, blue sheep are healthy and fatty, and for tahr, any season for meat and skin. Although extracting illegal resources like non-timber forest products (NTFPs) and hunting animals is prohibited (Khanal et al., 2018), local herders disclosed illegal activities, such as snares, to hunt blue sheep and pheasants, Lophophorus impejanus, and collection of timber and NTFPs, occur frequently. Uprety et al. (2021) strongly stress that mobilization of local people to provide strong intelligence is imperative for effectively fighting illegal wildlife trading, but it is limited due to lack of financial resources that is what is felt during this study period.

An indigenous gun was a common tool for hunting animals by $65 \%$ of users, whereas the remaining $35 \%$ use the trap. All hunters preferred to hunt inside the protected area due to their poor economic conditions. The core values of wildlife vs. hunters in this conservation area are non-prolific with less contribution by the latter.

Poaching and intense grazing can easily eliminate wild ungulates (Schaller, 1977; Aryal \& Subedi, 2016). Habitat loss and wildlife hunting pose a formidable challenge for wildlife conservation in Nepal's mountains. Hunting is observed as a serious threat in this protected and adjacent area. Darchula and Bajhang are becoming major hubs, with Tingkar and Saipal as the main outlets of illegal wildlife trade in western Nepal. Recently, Paudel et al. (2020) and Puri et al. (2020) reported Darchula as a major wildlife trade hub. Wildlife's long-term survival and sustainability depend on sufficiently large areas of suitable habitat and opportunities for dispersal between such areas (Harrison, 1991; Hanski, 1999). Blue sheep and musk deer are highly threatened due to hunting and mostly trapping to the later for the musk pods.

As per the Nature Conservation and Sustainable Hunting in $\mathrm{EU}$ (EC, 2000) following elements are important to enhance the mutual benefits between hunting and biodiversity conservation. There must be effective dialogue and partnership between hunters and environmentalists, farmers, landowners, park authorities, with an open mind and mutual understanding to transform conflicts into solutions; readiness to recognize that well-regulated hunting can be compatible with conservation objectives and contributes to biodiversity in many sites; better awareness-raising and training of hunters on conservation issues and hunting; full compliance with the law, a prerequisite to build trust and collaboration with others; a collection of good quality 
data; species and habitat monitoring and science-based management decisions.

\section{CONCLUSIONS}

The success of biodiversity conservation in ANCA has more to do with effective hunting management for social needs. Though the local people have gained ownership of conservation efforts, the uses of NTFPs and wildlife are rampant. Unless the community people of this area are made aware and uplifted economically, there may be a dramatic decline in blue sheep, tahr and goral populations. Banning hunting is not easy, and it is a major hurdle for the people because ANCA and adjoining districts like Bajhang and Bajura have a century-long tradition of hunting in their areas. The efforts on conservation programs could be more important than traditional livestock raising; otherwise, it would be too late after severe natural phenomena take their way. After careful consideration, hunters should agree to accept a ban on hunting in exchange for the potential employment opportunities and economic benefits associated with a conservation program. Wildlife authorities have to prove that, with the support and involvement of local people, wildlife conservation and management plans can succeed.

\section{ACKNOWLEDGEMENTS}

We would like to thank DNPWC for permitting us to undertake research studies in the conservation area. Dal Bahadur Lothyal and Bishan Lothyal had assisted us during our field trips, and we are highly acknowledged for their valuable support.

\section{AUTHOR CONTRIBUTIONS}

TBK carried out research and wrote the first draft of the manuscript. MKC designed the research concept, carried out research, and revised the final manuscript.

\section{CONFLICT OF INTEREST}

The authors declare no competing interests.

\section{DATA AVAILABILITY STATEMENT}

The data that support the findings of this study are available from the corresponding author, upon reasonable request.

\section{REFERENCES}

Aryal, A., \& Subedi, A. (2016). Conservation and Potential Habitat of the Himalayan Musk Deer, Moschus chrysogaster. Journal of Conservation Science, 2(2), 127-141.

Bowyer, R.T., Boyce, M.S., Goheen, J.R., \& Rachlov J.L. (2019). Conservation of the world's mammals: Status, protected areas, community efforts, and hunting. Journal of Mammalogy, 100(3), 923-941. http://doi.org/10.1093/jmam $\mathrm{mal} /$ gyy 180 .

Chalise, M. K. (2012). Report on presence-absence of Red Panda in Api NampaConservation Area, Darchula, Nepal.

Chalise, M.K. (2016). Nepalka Banyajantu, Nepal Biodiversity Research Society, Lalitpur, Vol. 4 p. 248.
Damm, G.R. (2008): Recreational Trophy Hunting: "What do we know and what should we do?" - In: Baldus,R. D.; Damm, G. R. \& Wollscheid, K. (eds.): Best Practices in Sustainable Hunting - A Guide to Best Practices from Around the World, pp. 5-11.

DNPWC. (2019). Biodiversity profile of the Api Nampa Conservation Area, Nepal. Department of National Parks and Wildlife Conservation, Kathmandu, Nepal, pp. 108.

EC. (2000). Sustainable Hunting and Natura 2000. European Commission. Retrieved August 16, 2021 from https://ec.europa.eu/environment/nature/info/pubs/docs / factsheets/hunting.pdf.

Frisina, M.R., \& Tareen, S.N.A. (2009). Exploitation prevents extinction: Case study of endangered Himalayan sheep and goats. In: Dickson, B., Hutton, J., \& Adams, W.M. (Eds.), Recreational bunting, conservation and rural livelihoods: science and practice (pp. 141-156), Blackwell Publishing.

Hanski, I. (1999). Habitat connectivity, habitat continuity, and metapopulations in dynamic landscapes. OIKOS, 87, 209219. https://doi.org/10.2307/3546736.

Harrison, S. (1991). Local extinction in a metapopulation context: an empirical evaluation. Biological Journal of the Linnean Society, 42, 73-88. https://doi.org/10.1111/j.10958312.1991.tb00552.x

IUCN. (2003). A New Era. World Conservation Bulletin. International Union for Conservation of Nature.

IUCN. (2006). IUCN Red List of threatened species. International Union for Conservation of Nature.

Jackson, R., \& Hunter, D.O. (1996). Snow leopard survey and conservation bandbook, 2nd Edition, International Snow Leopard Trust, Seattle, Washington and U.S. Geological Survey, Colorado.

Khanal, G., Poudyal, L., Devkota, B., Ranabhaat, R., \& Wegge, P. (2018). Status and conservation of the snow leopard in Api Nampa Conservation Area, Nepal. Oryx, 54(3), 421428.

Oli, K.P., Chaudhary, S., \& Sharma, U.R. (2013). Are Governance and Management Effective within Protected Areas of the Kanchenjunga Landscape (Bhutan, India and Nepal)? Parks, 19(1), 25-36.

Paudel, P.K., Acharya, K.P., Baral, H.S., Heinen, J.T., \& Jnawali, S.R. (2020). Trends, patterns and networks of illicit wildlife trade in Nepal: A synthesis. Conservation Science and Practice, 2(9), e247. https://doi.org/10.1111/csp2.247.

Puri, G., Timilsena, Y.P., Huettmann, F., Regmi, G.R., \& Lama, R.P. (2020). Poaching and illegal trade of wildlife: What Do the media say for the Nepali-Chinese and Nepali-Indian border? In G.R. Regmi, F. Huettmann (Eds.), HindukushHimalaya watersheds downhill: Landscape ecology and conservation perspectives (pp. 695-716), Springer Nature, Switzerland.

Schaller, G.B. (1977). Mountain monarchs. Chicago and London. University of Chicago Press.

Schaller, G.B., Junrang, R., \& Mingjiang, Q. (1988). Status of snow leopard Panthera uncia in Qinghai and Gansu Provinces, China. Biological Conservation 45, 179-194.

Uprety, Y., Chettri, N., Dhakal, M., Asselin, H., Chand, R., \& Chaudhary, R.P. (2021). Illegal wildlife trade is threatening conservation in the transboundary landscape of Western Himalaya. Journal for Nature Conservation, 59, 125952. https://doi.org/10.1016/j.jnc.2020.125952.

Yakha, T.B. (2014). Conservation status and ecology of Blue sheep (Pseudois nayaur). Voice of Bajra, 3(1) 68-74. 